BMJ Open Sport \& Exercise Medicine

\title{
Anterior cruciate ligament injury mechanisms through a neurocognition lens: implications for injury screening
}

\author{
Alli Gokeler (1) , ${ }^{1,2,3}$ Anne Benjaminse, ${ }^{4,5}$ Francesco Della Villa, ${ }^{6}$ Fillippo Tosarelli, ${ }^{6}$ \\ Evert Verhagen (D) , ${ }^{1}$ Jochen Baumeister ${ }^{2}$
}

To cite: Gokeler A, Benjaminse A, Della Villa F, et al. Anterior cruciate ligament injury mechanisms through a neurocognition Iens: implications for injury screening. BMJ Open Sport \& Exercise Medicine 2021;7:e001091. doi:10.1136/ bmjsem-2021-001091

Check for updates

C Author(s) (or their employer(s)) 2021. Re-use permitted under CC BY-NC. No commercial re-use. See rights and permissions. Published by BMJ.

${ }^{1}$ Amsterdam Collaboration on Health \& Safety in Sports, Department of Public and Occupational Health, Amsterdam Movement Sciences, Amsterdam UMC, Amsterdam, Netherlands

${ }^{2}$ Exercise Science and Neuroscience, Department Exercise \& Health, Faculty of Science, Paderborn University, Paderborn, Germany ${ }^{3}$ OCON Center of Orthopaedic Surgery and Sports Medicine, Hengelo, Netherlands ${ }^{4}$ School of Sport Studies, Hanze University of Applied Sciences, Groningen, The Netherlands ${ }^{5}$ Center for Human Movement Science, University Medical Center Groningen, University of Groningen, Groningen, Netherlands

${ }^{6}$ Education and Research Department, FIFA Medical Centre of Excellence, Isokinetic Medical Group, Bologna, Italy

Correspondence to Dr Alli Gokeler;

a.gokeler@amsterdamumc.nl

\section{ABSTRACT}

Athletes in team sports have to quickly visually perceive actions of opponents and teammates while executing their own movements. These continuous actions are performed under time pressure and may contribute to a non-contact ACL injury. However, ACL injury screening and prevention programmes are primarily based on standardised movements in a predictable environment. The sports environment provides much greater cognitive demand because athletes must attend their attention to numerous external stimuli and inhibit impulsive actions. Any deficit or delay in attentional processing may contribute to an inability to correct potential errors in complex coordination, resulting in knee positions that increase the ACL injury risk. In this viewpoint, we advocate that ACL injury screening should include the sports specific neurocognitive demands.

\section{INTRODUCTION \\ Think beyond biomechanics}

Research on ACL injury mechanisms in the laboratory has contributed to our knowledge of the biomechanical settings and neuromuscular risk factors. ${ }^{12}$ Usually, an endpoint of movements linked to the ACL injury mechanism such as knee valgus combined with a nearly extended knee is reported. ${ }^{1}$ In addition, testing athletes in the lab often consists of a relatively consistent and predictable environment with self-paced predictable movements (closed motor skills). Bittencourt et $a \hat{l}$ proposed a complex system approach to enhance the understanding of injury aetiology. Briefly, this approach highlights a non-linear interaction between risk factors from different dimensions (biomechanical, psychological/neurocognitive, physiological characteristics) as a web of determinants and how these may contribute to injuries. ${ }^{3}$ ACL injury risk research could benefit from such a comprehensive injury causation model. Bahr and Krosshaug ${ }^{1}$ proposed a conceptual model in which an inciting event not only includes information about the biomechanical characteristics, but also about the playing

\section{Key messages}

What is already known

- ACL injuries are predominantly viewed from a biomechanical perspective

- ACL injury screening is commonly done with predictable closed-skills tasks

What are the new findings

- Neurcognitive errors may contribute to ACL injuries

- Open skill tasks should be considered to assess coordination

- ACL injury screening should include sport specific neurocognitive demands

situation and the behaviour of the athlete and their opponent(s). Descriptive video analyses have shown that athlete behaviour and playing situations are relevant to ACL injury mechanisms. ${ }^{4}$ For example, in team ball sports, the athletes are immersed in a rapidly changing, unpredictable and externally paced environment. In these open-skill sports, perception-action coupling is crucial, as the athlete has to perceive their own action opportunities as well as those of opponents and teammates before deciding on a movement solution, all of these often under time pressure. ${ }^{5}$ Any deficit or delay in sensory or attentional processing may lead to potential coordination errors and result in high risk knee movements under high temporal constraints, posing a challenge to maintain coordinated control of movements. ${ }^{6}$ Indeed, it has been estimated that ACL injuries occur approximately $40 \mathrm{~ms}$ after initial contact. ${ }^{7}$ Higher level football players, compared with lower-level players, exhibit safer biomechanics in a cognitively demanding task. ${ }^{8}$

The above mentioned suggest the value of including neurocognition when investigating an ACL injury mechanism and may have implications for injury screening. ${ }^{9}$ This viewpoint's primary aim is to present insight from the neurocognition domain to enhance our understanding of ACL injury mechanisms. 
This approach may have implications for future developments of ACL injury screening programmes.

\section{Neurocognition: what is it, and how does it apply to the ACL injury mechanism?}

Neurocognition is defined as cognitive processes or functioning understood in relation to the specific neural mechanisms by which they occur in the brain and any impairment of these mechanisms. Higher level neurocognitive functions, also referred to as executive functions are essential in tasks that demand concentration, coordination and control to override internal or external stimuli. ${ }^{10}$ Executive functions refer to the ability to coordinate cognitive, emotional and motor processes as the set of adaptive behaviours allowing people to successfully navigate the environment by shifting and adapting to changing environmental cues and needs. ${ }^{11}$ They can be divided into the components working memory, inhibition control and cognitive flexibility. ${ }^{10}$ Inhibitory control involves the ability to control attention, behaviour, thoughts and/or emotions in order to cancel strong internal predispositions or external temptation, and instead act in a more appropriate way. ${ }^{10}$ As such, inhibition plays an important role in selective attention, that is, the deployment of attentional focus on task relevant features of for example, the rapidly changing situations on the field. Inhibitory control is related to working memory, because in order to relate multiple ideas or get facts together one must be able to resist focusing only on one thing. Cognitive flexibility has been defined as the capacity to adapt strategies of cognitive processing to new conditions. ${ }^{10}$ Lower order cognitive functions include for example, visual attention, processing speed (eg, reaction time) and dual-tasking. ${ }^{10}$

Information processing speed refers to the time someone needs to process new information and to the time needed to retrieve stored information from memory. ${ }^{10}$ Information processing speed is a basic cognitive function, which is needed for more complex functions such as working memory. ${ }^{10}$ Reaction time is a measure of how quickly an athlete can respond to a particular stimulus. ${ }^{11}$

It is the ability to detect, process and respond to a stimulus. Perception is the organisation, identification and interpretation of sensory information in order to represent and understand the presented information. ${ }^{11}$ Dual tasking or multitasking is the attempt to perform two or more tasks simultaneously. ${ }^{10}{ }^{11}$ When multitasking, people make more mistakes or perform the tasks more slowly. These domains are top-down in nature, with the bottom referring to more basic sensory and perceptual processes and the top referring to elements of executive functioning and cognitive control. ${ }^{10}$ There is substantial overlap between the domains suggesting that the cognitive constructs may not be as separable as traditionally thought. For this viewpoint, we will mainly focus on inhibitory control pertaining to the possible contribution to ACL injuries.

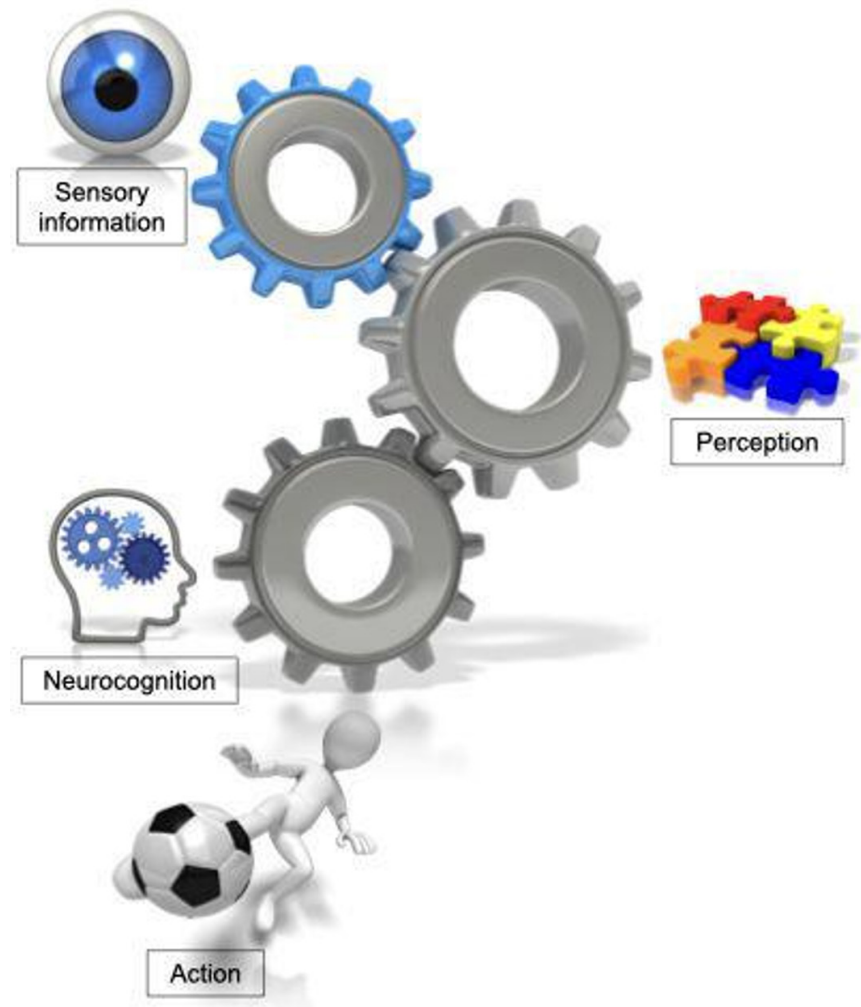

Figure 1 Model displaying the process from obtaining information from the environment, perceiving and processing this information, leading to a selected motor action.

\section{Translated to the neurocognitive demands on the field}

Expert performance in sport constitutes a combination of both motor and perceptual-cognitive skills, which address an athlete's ability to locate, identify, and process information in a specific environment (figure 1) ${ }^{12}$ Team ball sports athletes require quick and effective perception and interpretation of the opportunities to execute the successful performance. ${ }^{13}$ An example is an athlete's capability to interpret and identify an opponent's movement before those actions are executed.

Waldén et $a l^{14}$ identified the most common injury mechanism of non-contact ACL injury mechanisms in professional football, which consisted of pressing with a defensive action towards the opponent. However, elite football players are true masters in making deceptive movements. Subsequently, opponents must be able to predict the outcome of deceptive moves. This may pose a challenge for a defender, who is pressing, anticipating a particular direction of the ball played, but at the last moment, the attacker is faking his action. In a fraction of a second, the defender has to change the movement quickly which poses a significant challenge for the motor system to change an already planned or initiated movement. Viewed through a neurocognition lens, errors in inhibitory control may have been at stake. Control of impulsive behaviour may have allowed the player slightly more time to gain relevant information on the opponent's intentional movement and plan his own action accordingly. 

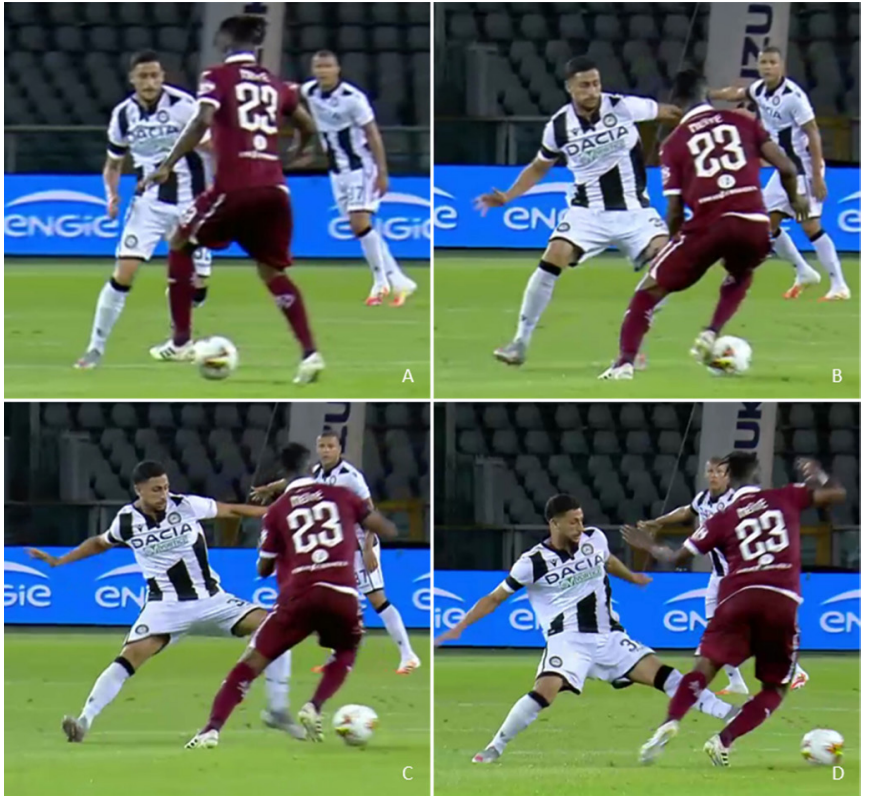

Figure 2 (A and B) Defender: reading opponents body language and anticipating. Attacker: makes a deceiving action. (C and D) Defender: rapid change of movement from right to left, reacting to attackers deceiving action. (D) Defender ruptures his right ACL.

Selective attention is the athlete's ability to focus on a relevant situation on the field and suppressing attention to other stimuli that are not relevant. ${ }^{10}$ Lacking the capability to redirect or sustain attention from one stimulus to the next may result in a loss of spatial awareness and disrupt motor control. ${ }^{15}$ Video analysis of actual ACL injuries in high school, college and professional basketball indicated that the injured player's attention was commonly focused at the basket rim, followed by attention directed at the opponent or a focus on the ball. ${ }^{16}$ Such divided attention means less attention for the athlete's own movements and may have contributed to the ACL injury mechanism, as less time is available to correct or change an already initiated movement (figure 2).

\section{Adding neurocognition to injury screening}

Various neuromuscular screening tests have been developed to identify athletes at risk for an ACL injury. ${ }^{217}$ These tests are considered closed skills (predictable in a controlled environment) and not reflective of demands on the field. As outlined in the injury mechanism section, neurocognitive errors may contribute to actual ACL injuries. To enhance ACL injury screening test validity, these tests should also include neurocognitive demands.

Many domain-generic neurocognitive tests are available to assess higher executive functions such as inhibitory control and working memory. Examples of inhibitory control measures include the Stroop task, Flanker task, go/no-go tasks and the stop-signal task. ${ }^{10}$ Examples for working memory are the N-back task, forward or backwards-digit span tasks and the Corsi block test. ${ }^{10}$

To close the gap between isolated measurements of the domain-generic neurocognition and motor skills, we propose an integrated and therefore complex assessment with open-skill motor tasks where neurocognitive demands are added. It has been shown that single-leg hop performance (jump distance) deficits were amplified by the addition of neurocognitive challenges. ${ }^{18}$ Similarly, athletes have demonstrated alterations in lower extremity biomechanics with drop landing trials that incorporated temporal constraints on decision-making compared with standard drop landing trials. ${ }^{19}{ }^{20}$ Also attending to a ball while sidestep cutting resulted in more trunk extension and less lateral trunk flexion toward the cutting direction. ${ }^{21}$ A shortcoming of current tests is that they usually follow simple motor skills based on reaction paradigms. Considering that cognitive processes during team sports do not only rely on reactive patterns, but also on working memory and inhibitory control where information needs to be stored and distractors need to be ignored. More complex perceptual-cognitive stimuli need to be provided during complex motor tasks for a more ecologically valid assessment. Technologies such as virtual reality, apps and light systems providing stimuli could help in developing more sport-specific screening tests.

\section{CONCLUSION}

There is a need to broaden our scope of ACL injury mechanisms and screening for ACL injury. Integrating a neurocognitive approach to the existing biomechanical and neuromuscular approach would enhance our understanding of the ACL injury mechanisms' complexity. Currently, ACL injury screening typically include preplanned motor skills in a predictable environment and lacks a transfer towards the neurocognitive demands an athlete faces in unpredictable and fast changing complex situations while on the field. Subsequently, this knowledge may help develop future ACL injury risk screening tests and prevention protocols that connect these neurocognitive and biomechanical factors in a representative test design reflecting the demands of the sport.

\section{Twitter Alli Gokeler @AlliGokeler and Evert Verhagen @evertverhagen}

Acknowledgements We are grateful to Dr Federico Ferri and Sky Sport Italia for the kind collaboration in providing the access and permission to use of figure 2. The authors thank the player Rolando Mandragora for the permission to use the frames in figure 2 .

Contributors AG conceptualised the initial idea for the paper and outlined the current state of the ACL injury literature and placed the new approach within existing theories of neurocognition. FDV, FT, JB and EV jointly developed the neurocognitive approach to ACL injury. JB and EV contributed an intersectional lens, and an overall critical review of the paper. All authors approved the final version of the manuscript.

Funding The authors have not declared a specific grant for this research from any funding agency in the public, commercial or not-for-profit sectors.

Competing interests None declared.

Patient consent for publication Not required.

Provenance and peer review Not commissioned; externally peer reviewed. 
Open access This is an open access article distributed in accordance with the Creative Commons Attribution Non Commercial (CC BY-NC 4.0) license, which permits others to distribute, remix, adapt, build upon this work non-commercially, and license their derivative works on different terms, provided the original work is properly cited, appropriate credit is given, any changes made indicated, and the use is non-commercial. See: http://creativecommons.org/licenses/by-nc/4.0/.

ORCID iDs

Alli Gokeler http://orcid.org/0000-0002-6427-4225

Evert Verhagen http://orcid.org/0000-0001-9227-8234

\section{REFERENCES}

1 Bahr R, Krosshaug T. Understanding injury mechanisms: a key component of preventing injuries in sport. $\mathrm{Br} J$ Sports Med 2005;39:324-9.

2 Hewett TE, Myer GD, Ford KR, et al. Biomechanical measures of neuromuscular control and valgus loading of the knee predict anterior cruciate ligament injury risk in female athletes: a prospective study. Am J Sports Med 2005;33:492-501.

3 Bittencourt NFN, Meeuwisse WH, Mendonça LD, et al. Complex systems approach for sports injuries: moving from risk factor identification to injury pattern recognition-narrative review and new concept. Br J Sports Med 2016;50:1309-14.

4 Della Villa F, Buckthorpe M, Grassi A, et al. Systematic video analysis of ACL injuries in professional male football (soccer): injury mechanisms, situational patterns and biomechanics study on 134 consecutive cases. Br J Sports Med 2020;54:1423-32.

5 Wang $\mathrm{C}-\mathrm{H}$, Chang $\mathrm{C}-\mathrm{C}$, Liang Y-M, et al. Open vs. closed skill sports and the modulation of inhibitory control. PLoS One 2013;8:e55773.

6 Swanik CB, "Buz" SC, Brains. Brains and Sprains: the brain's role in noncontact anterior cruciate ligament injuries. J Athl Train 2015;50:1100-2.

7 Koga H, Nakamae A, Shima Y, et al. Mechanisms for noncontact anterior cruciate ligament injuries: knee joint kinematics in 10 injury situations from female team handball and basketball. Am J Sports Med 2010;38:2218-25.

8 Lee MJC, Lloyd DG, Lay BS, et al. Effects of different visual stimuli on postures and knee moments during sidestepping. Med Sci Sports Exerc 2013;45:1740-8.
9 Swanik CB, Covassin T, Stearne DJ, et al. The relationship between neurocognitive function and noncontact anterior cruciate ligament injuries. Am J Sports Med 2007;35:943-8.

10 Diamond A. Executive functions. Annu Rev Psychol 2013;64:135-68.

11 Jurado MB, Rosselli M. The elusive nature of executive functions: a review of our current understanding. Neuropsychol Rev 2007;17:213-33.

12 Broadbent DP, Causer J, Williams AM, et al. Perceptual-cognitive skill training and its transfer to expert performance in the field: future research directions. Eur J Sport Sci 2015;15:322-31.

13 Williams AM, Ward P, Smeeton NJ, et al. Developing anticipation skills in tennis using on-court instruction: perception versus perception and action. J Appl Sport Psychol 2004;16:350-60.

14 Waldén M, Krosshaug T, Bjørneboe J, et al. Three distinct mechanisms predominate in non-contact anterior cruciate ligament injuries in male professional football players: a systematic video analysis of 39 cases. Br J Sports Med 2015;49:1452-60.

15 Thompson HW, McKinley PA. Landing from a jump: the role of vision when landing from known and unknown heights. Neuroreport 1995;6:581-4.

16 Krosshaug T, Nakamae A, Boden BP, et al. Mechanisms of anterior cruciate ligament injury in basketball: video analysis of 39 cases. Am J Sports Med 2007;35:9p.

17 Padua DA, Marshall SW, Boling MC, et al. The landing error scoring system (less) is a valid and reliable clinical assessment tool of jumplanding biomechanics: the JUMP-ACL study. Am J Sports Med 2009;37:1996-2002

18 Millikan N, Grooms DR, Hoffman B, et al. The development and reliability of 4 clinical neurocognitive Single-Leg hop tests: implications for return to activity decision-making. J Sport Rehabil 2019;28:536-44.

19 Herman DC, Barth JT. Drop-Jump landing varies with baseline Neurocognition: implications for anterior cruciate ligament injury risk and prevention. Am J Sports Med 2016;44:2347-53.

20 Giesche F, Wilke J, Engeroff T, et al. Are biomechanical stability deficits during unplanned single-leg landings related to specific markers of cognitive function? J Sci Med Sport 2020;23:82-8.

21 Norte GE, Frendt TR, Murray AM, et al. Influence of anticipation and motor-motor task performance on cutting biomechanics in healthy men. J Athl Train 2020;55:834-42. 